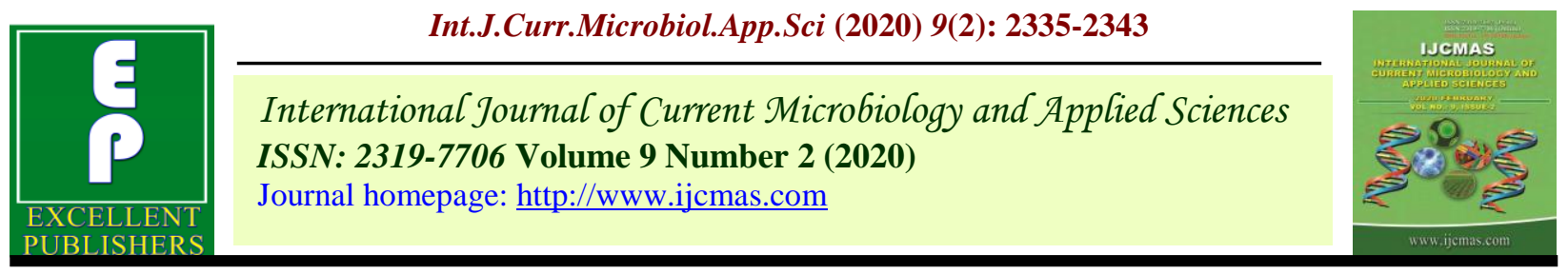

Original Research Article

https://doi.org/10.20546/ijcmas.2020.902.265

\title{
Screening for Heat Tolerant Traits in Wheat (Triticum aestivum L.) Genotypes by Physio-biochemical Markers
}

\author{
Prabhat Kumar Singh ${ }^{1 *}$, Shambhoo Prasad ${ }^{1}$, Abhishek Kumar Verma ${ }^{1}$, Babu Lal ${ }^{2}$, \\ Reesu Singh ${ }^{1}$, Sumant Pratap Singh ${ }^{1}$ and D.K. Dwivedi ${ }^{1}$
}

${ }^{1}$ Department of Plant Molecular Biology and Genetic Engineering, ${ }^{2}$ Department of Agriculture Statistics, Acharya Narendra Deva University of Agriculture \& Technology, Kumarganj, Ayodhya-224229 (U.P.) India

*Corresponding author

\section{A B S T R A C T}

Keywords

Wheat, Heat stress, MSI, CSI, CTD,

Stay green duration, yield components

Article Info

Accepted:

18January 2020

Available Online:

10 February 2020
An experiment was conducted with wheat genotypes Halna, PBW-343, Raj-3765, K-9006, HD-2733, K-8962, NW-1014, NW-1067, UP-2338 and DBW-14 to evaluate heat tolerant in wheat at instructional farm and in the laboratory of Plant Molecular Biology and Genetic Engineering, Acharya Narendra Deva University of Agriculture and Technology, Kumarganj, Ayodhya during rabi season of 2018-2019. Heat stress was induced by delayed sowing 35 days from normal date of sowing (25 November) so that delay sown wheat genotypes could experience heat stress at reproductive stage. Heat tolerant wheat genotypes screened on the basis of Membrane Stability Index (MSI), Chlorophyll Stability Index (CSI), stay green condition and Canopy Temperature Depression (CTD). High MSI, CSI and CTD were recorded in DBW-14, NW-1014 and Halna over other genotypes. These genotypes also showed less percent reduction in plant height, tiller number, spike length, number of grains per spike, test weight and grain yield per plant over control under heat stress regimes. Therefore MSI, CSI and CTD can be used as screening criteria for heat tolerant traits in wheat.

\section{Introduction}

Wheat (Triticum aestivum L.) is one of the principal cereal crops grown worldwide and one of the important staples of nearly 2.5 billion of world population. Wheat is the major staple food crop, providing almost half of all calories in the region of North Africa and West and Central Asia. Being next to rice, wheat constitutes one of the key sources of protein in least developed countries and middle-income nations and in terms of calories and dietary intake. The crop being cultivated as winter and spring in the world, winter wheat is grown in cold countries like Europe, the USA, Australia, Russian Federation, etc., while spring wheat is grown in Asia and in some parts of the USA. India, being blessed and enriched with a diverse agro ecological condition, ensuring food and nutrition security to a majority of the Indian population (Ramadas et al., 2019). 
In India the wheat crop has been cultivated in about 30 million hectares (14\% of global area) to produce the all time highest output of 99.70 million tonnes of wheat $(13.64 \%$ of world production) with a record average productivity of $3371 \mathrm{~kg} / \mathrm{ha}$ (2018). The wheat is one of the cheapest sources of energy, provides a major share of protein $(20 \%)$ and calorie intake (19\%) from consumption. Wheat is accessible across the country and consumed as various processed forms from prehistoric times (Ramadas et al., 2019). Wheat as a cool season crop, it has as an optimal growing temperature during reproductive stage of $15{ }^{\circ} \mathrm{C}$ and for every degree Celsius temperature above this optimum leads to reduction in yield of 3\%$4 \%$ has been observed (Wardlaw et al., 1989). However, it has been reported that the average worldwide temperature is increasing at a rate of $0.18{ }^{\circ} \mathrm{C}$ every ten years (Hansen $e t$ al., 2012). Thus, the likely impact of heat stress in wheat has recently attracted increasing attention (Moriondo et al., 2011).

Heat stress causes injury to cellular structure and disturbs various metabolic pathways, specifically photosynthesis, membrane thermo stability, and starch synthesis related pathways (Larkindale et al., 2002). Denaturation of proteins and increased levels of unsaturated fatty acids caused by heat stress disrupt water, ion, and organic solute movement across membranes, leading to increased cell membrane permeability, and in turn, inhibition of cellular function (Cossani et al., 2012). Temperature can modify developmental and growth rates in plants. Similarly, heat stress affects agronomic traits at every growth stage, but the before flowering stage and anthesis period are comparatively more sensitive to high temperature compared to after flowering stages (Limbalkar et al., 2018). Heat stress affects the metabolic pathways at every stage of life of wheat finally leading to yield reduction, the effect of high temperature is particularly severe during grain filling; these losses may be up to $40 \%$ under severe stress. Other effects of high temperatures are decreased grain weight, early senescence, shrivelled grains, reduced starch accumulation, and altered starch-lipid composition in grains, lower seed germination and loss of vigour. Grain filling duration has been used as a parameter to identify heat tolerant wheat genotypes (Ali et al., 2018).

Extremes of temperature at sensitive developmental stages are especially detrimental as temperatures above $30^{\circ} \mathrm{C}$ around anthesis can damage pollen formation and reduce yield. It is established that many physiological traits / parameters viz; grain filling duration (GFD), canopy temperature (CT) have strong correlation with terminal heat tolerance (THT). It is assumed that reduced GFD will avoid the damage done due to terminal heat stress, while a low $\mathrm{CT}$ will help the plant withstand terminal heat stress. In view of this, both GFD and CT have been used while selecting for higher wheat yields under high temperature at the time of maturity and thus can be effectively utilized for QTL analysis as parameters for terminal heat tolerance.

\section{Materials and Methods}

Wheat genotypes Halna, PBW-343, Raj-3765, K-9006, HD-2733, K-8962, NW-1014, NW1067, UP-2338 and DBW-14 were sown at Student Instructional Farm of Acharya Narendra Deva University of Agriculture and Technology, Kumarganj, Ayodhya. (U.P.) during rabi season 2018-19. The treatment of heat stress was given by delayed sowing of 35 days (15 January 2019). So that the reproductive phase of wheat could experience severe heat stress. General agronomical practices were adopted time to time as per need of the crop. The temperature at the time 
of grain filling stage varied from $36^{\circ} \mathrm{C}$ to $39^{\circ} \mathrm{C}$ in delayed sown wheat crop. Total chlorophyll content was recorded at reproductive stage as SPAD (Dhopte and Livera, 1989). A day to stay green duration was recorded from $100 \%$ greenness to reduction of greenness start. Plant height was recorded from base of plant to base of spike of three plants and average out to one. Tiller number of three plants were recorded separately and average out to one. Days to $100 \%$ flowering was recorded from date of sowing to $100 \%$ flowering of three plants and average out to one as considered. Days to $100 \%$ maturity was recorded from sowing to $100 \%$ physiological maturity of three plants and average out to one as considered.

Number of spikes of three plants were recorded and average out to one as spike plant $^{-1}$. Main Spike length of three plants were recorded and average out to one as spike length. Number of grain spike ${ }^{-1}$ were recorded by selecting main spike of three plants and average out to one as considered grains spike 1 . Test weight was recorded as weight of 1000 seeds in gram. Seed weight of three randomly selected plants were recorded and average out to one as grain yield plant ${ }^{-1}$.

\section{Results and Discussion}

\section{Membrane Stability Index}

The figure clearly showed the stability of membrane was highly affected by heat stress condition at reproductive stage (Fig.1). Maximum MSI was recorded DBW-14 (58.9) and minimum PBW-343 (37.1) under heat stress condition. In all wheat genotypes, the integrity of cell membrane disturbed under heat stress condition. The low MSI was noted in susceptible wheat lines due to more leakage of electrolyte under heat stress condition.

Cell membrane stability, a measure of electrolyte diffusion resulting from heat- induced cell membrane leakage, has been used to screen and evaluate different wheat genotypes for thermal tolerance (Sairam et al., 1994).

\section{Chlorophyll stability index}

The chlorophyll stability index was highly affected by heat stress condition under reproductive stage of wheat genotypes (Fig.2). Maximum CSI was recorded in NW1014 (57.86\%) while minimum Raj-3765 (21.76\%) under control condition. The low CSI was noted in susceptible wheat lines due to more leakage of electrolyte under heat stress condition. In reproductive stage under heat stress condition the maximum CSI reduction was recorded in NW-1067 (48.1\%), DBW-14 (44.5\%) and K-9006 (42.7\%) followed by K-8962 (36.7\%) and PBW-343 $(31.4 \%)$ whereas, minimum recorded in Halna (21.2\%). Increasing the chlorophyll content in crops may be an effective way to increase biomass production and grain yield (Wang et al., 2008).

\section{Canopy temperature depression}

Canopy temperature depression significantly varied in wheat genotypes under heat stress condition (Fig. 3). High CTD was recorded in Halna (5.5), HD-2733 (4.8) and NW-1014 (4.8) while less in PBW-343 (4.1) and Raj3765 (5) under heat stress condition. Canopy temperature is a promising trait for identifying heat and drought tolerance and canopy temperature depression (CTD) has been shown to correlate well with the transpiration status in crops like wheat and rice (Fukuoka, 2005, Kumar et al., 2015).

\section{Plant height}

Wheat genotypes showed genetic variability in plant height (Fig. 4). The maximum plant height was noted in K-8962 $(90.67 \mathrm{~cm})$ and minimum in HD-2733 $(64.33 \mathrm{~cm})$ under 
control condition. The Stability in plant was highly fluctuated under heat stress in wheat genotypes due to their generic level of heat tolerance. The maximum reduction was recorded in HD-2733 (35.22\%) followed by NW-1067 (30.74\%) and K-9006 (24.53\%) while minimum in Halna (12.50\%) followed by Raj-3765, K-8962, UP-2338, DBW-14 and NW-1014 in terms of percent reduction over control.

\section{Tiller number per plant}

Wheat genotypes showed significant variability in number of tillers per plant (Fig.5). Under control condition the maximum tiller number was recorded in $\mathrm{K}$ 9006 (14.00), and minimum in K-8962 (7.33). The heat stress had significant effect on tiller number per plant and reduced it in all wheat genotypes. The minimum per cent reduction in tiller numbers was recorded in DBW-14 (10.78) and maximum in PBW-343 (48.69) in heat stress regimes. DBW-14, Raj-3765 and NW-1014 showed superiority over other genotypes due to low per cent reduction in tiller number over control heat stress condition. Heat stress during early vegetative stage affects the tiller numbers and resultantly it also affects the number of spikelet per plant, resulting in reduced sink capacity and future source capability of the plants (Sharma et al., 2001).

\section{Spike length}

There were significant variations in spike length in different wheat genotypes under control condition and heat stress condition (Fig. 6). The maximum spike length was noted in K-9006 and minimum Halna under the control conditions. Under heat stress conditions the length of spike was not maintained as under control condition. Heat stress significantly reduced spike length. Genotypes showed like Halna (5.35), Raj-
3765 (5.82), PBW-343 (7.87), UP-2338 (7.89) and HD-2733 (8.73) per cent reduction respectively over control and statistically superior over other variety. The high per cent reduction was recorded in NW-1067 (19.02), K-9006 (15.19).

\section{Number of grains per spike}

Wheat genotypes showed genetic variability in number of grains spike ${ }^{-1}$ under control and stress condition (Fig. 7). High number of grains in main spike was noted in K-8962 (62.00), DBW-14 (58.67) and NW-1014 (56.00) while less number of grains recorded in Halna (35.67), PBW-343 (40.67) and K9006 (47.67). Heat stress reduction the grains in main spike irrespective of wheat genotypes. High reduction in number of grains in main spike was obtained in PBW-343 (58.20\%), HD-2733 (46.75\%) and NW-1014 (44.05\%) while less in UP-2338 (18.54\%), Raj-3765 (19.86\%) and K-9006 (21.69\%) under heat stress regions.

\section{Yield per plant}

The genetic variability was recorded in yield per plant of wheat varieties (Fig. 8). Under control condition K-9006, HD-2733 and NW1067 showed 15.25, 15.23 and $14.10 \mathrm{~g}$ grain yield per plant respectively and superior over other varieties. But under stress condition it persistency was not maintained as control condition and thus maximum per cent reduction was recorded in K-9006 (47.08) followed by HD-2733 (45.96) and NW-1067 (35.67). The minimum per cent reduction was noted in Raj-3765 (20.32\%) and statistically significant of over other in yield persistency under heat stress condition.

\section{Test weight}

There was significant variation in test weight recorded in wheat varieties under control and 
heat stress condition (Fig. 9). The varieties that showed maximum test weight under control condition were DBW-14 (51.48), HD2733 (46.83), Raj-3765 (46.67), UP-2338 (45.33), PBW-343 (43.80) and lowest test weight containing varieties were K-8962 (31.60), Halna (37.83), NW-1067 (38.13) and NW-1014 (40.12).

The test weight of all varieties was markedly reduced in heat stress condition. The per cent reduction becomes high as temperature increased. The maximum reduction under control heat stress was recorded in K-9006 $(41.27 \%)$, and followed by HD-2733 $(40.59 \%)$ and NW-1067 (34.38\%). The minimum reduction was recorded in UP-2338 (22.85\%) followed by Raj-3765 (24.94\%), Halna (26.06\%), K-8962 (26.26\%), DBW-14 (26.82\%), PBW-343 (27.05\%) and NW-1014 $(27.29 \%)$ showed minimum reduction.

Fig.1 Membrane stability index of wheat genotypes

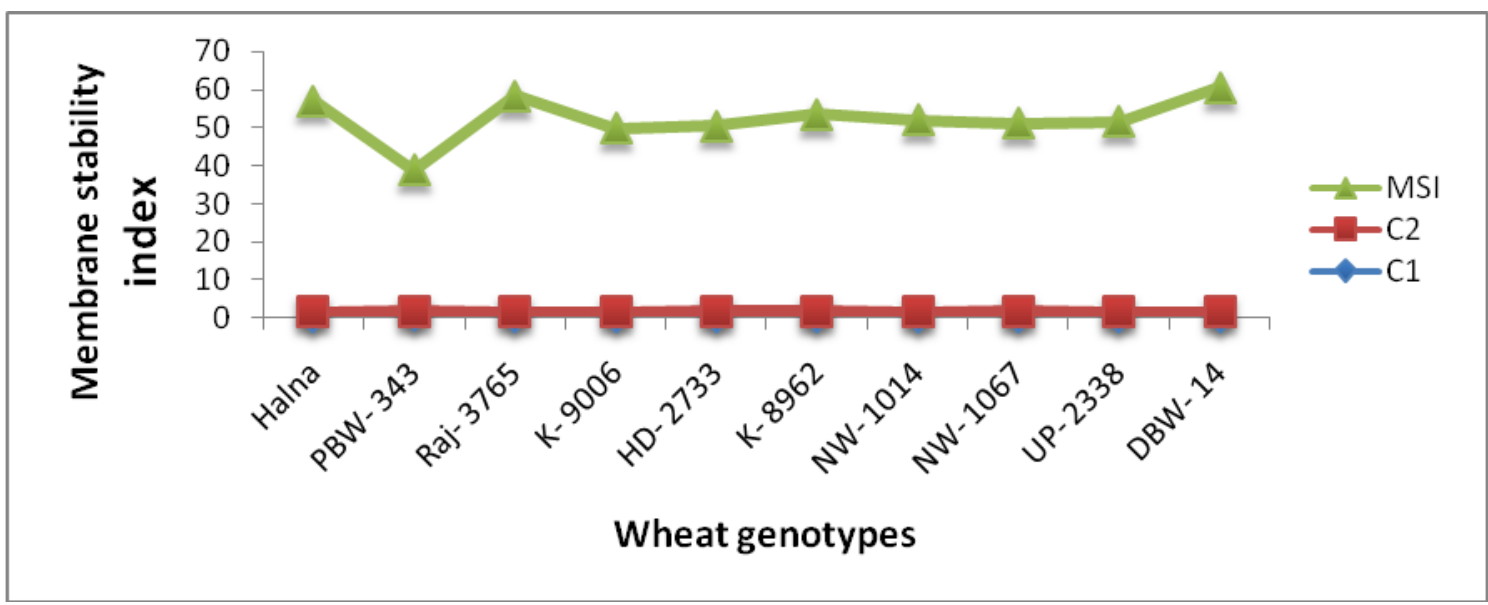

Fig.2 Chlorophyll stability index and its percent reduction of wheat genotypes over control under heat stress condition at reproductive stage

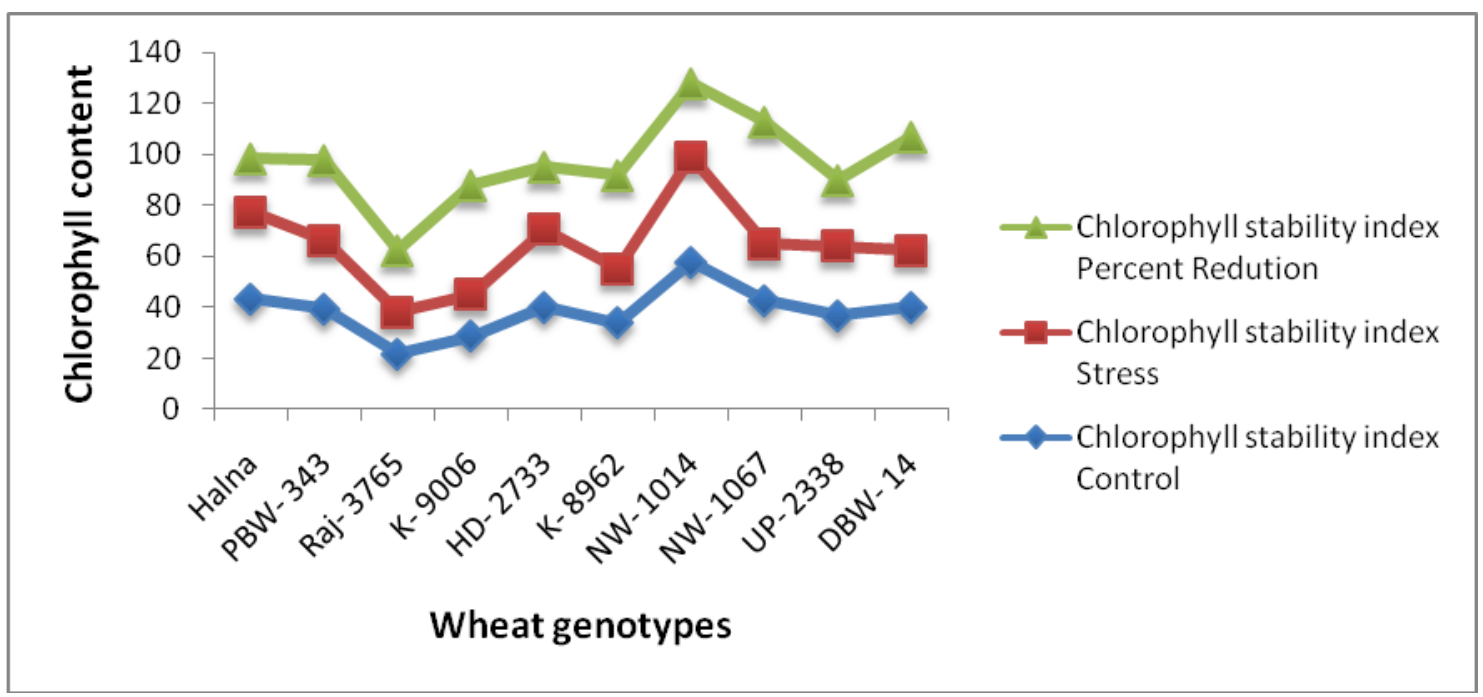


Fig.3 Effect of heat stress on CTD of wheat genotypes

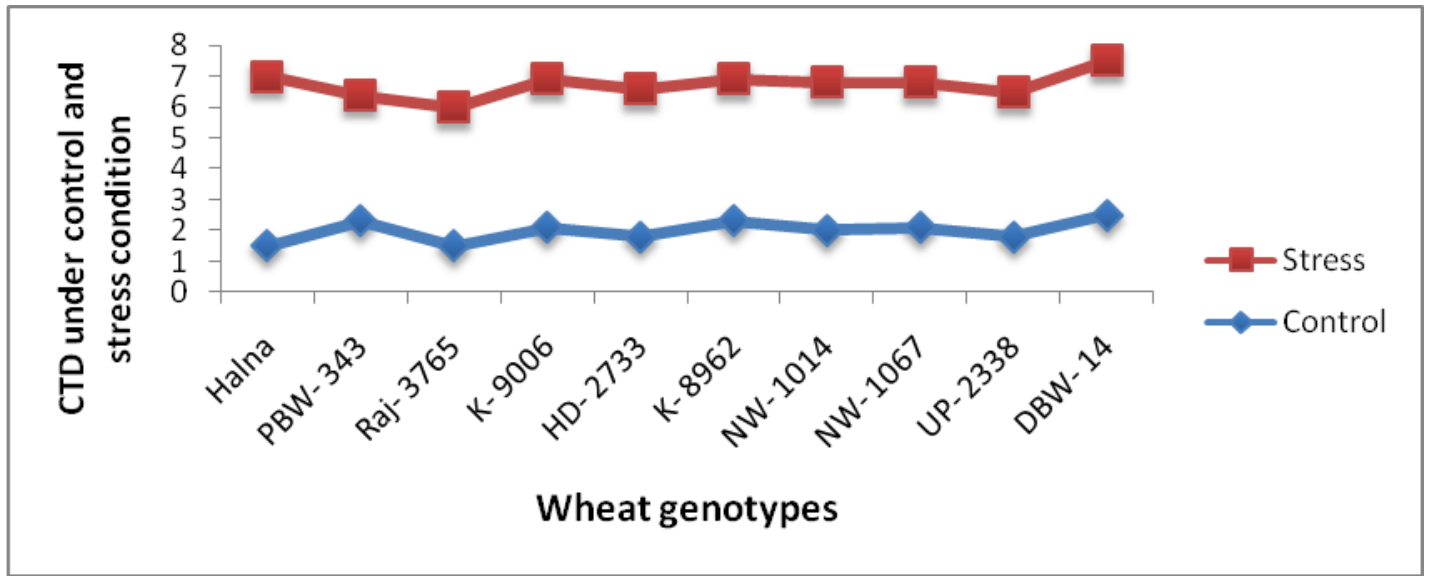

Fig.4 Plant height $(\mathrm{cm})$ and its percent reduction over control of wheat genotypes under heat stress condition

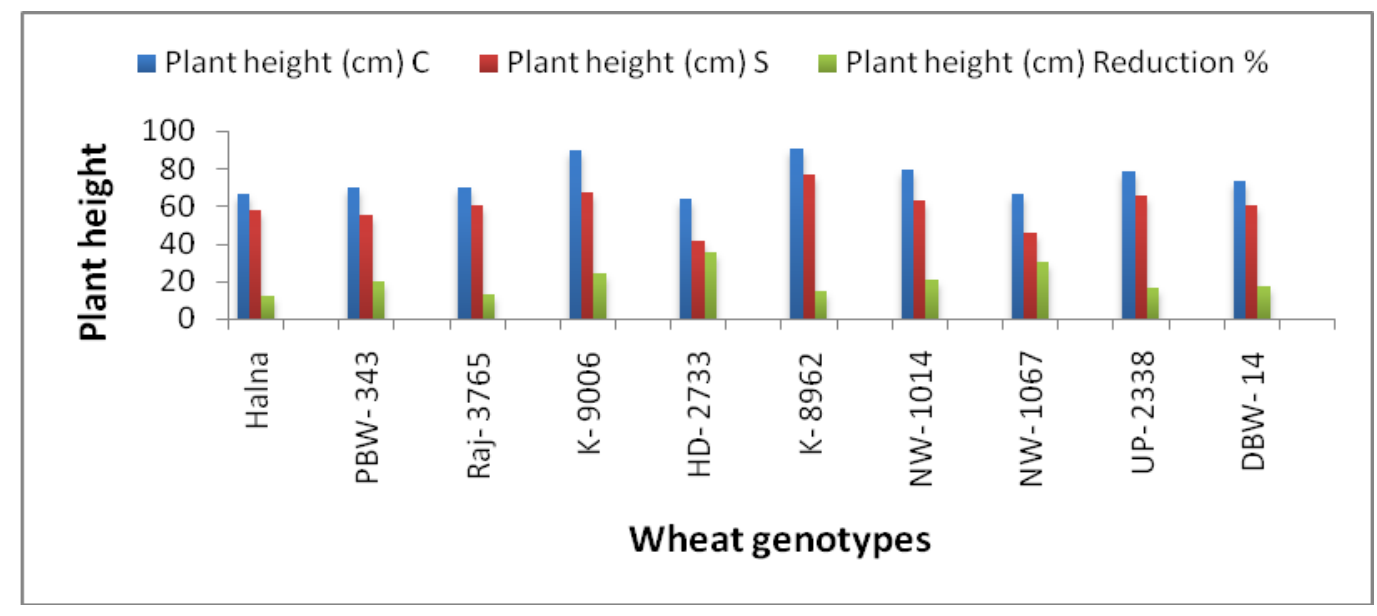

Fig.5 Tiller number per plant and its percent reduction over control of wheat genotypes under heat stress condition

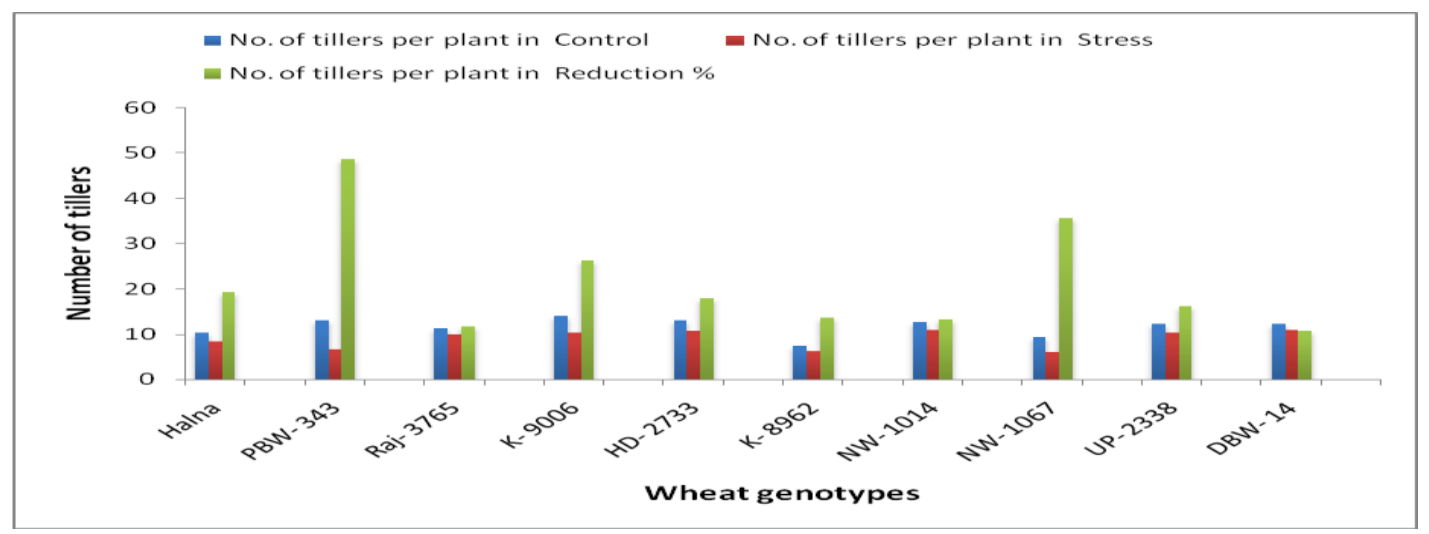


Fig.6 Spike length $(\mathrm{cm})$ and its percent reduction over control of wheat genotypes under heat stress condition

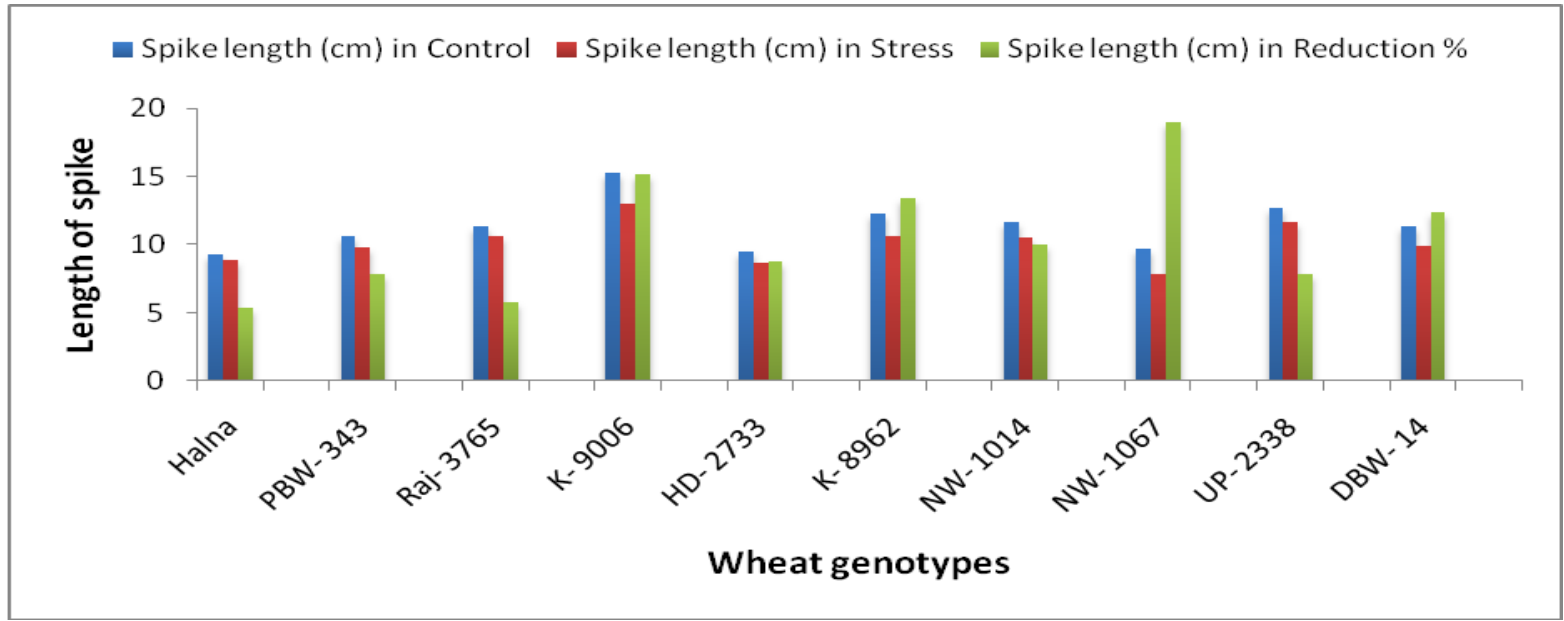

Fig.7 Number of grains in main spike and its percent reduction of wheat genotypes over control under heat stress condition

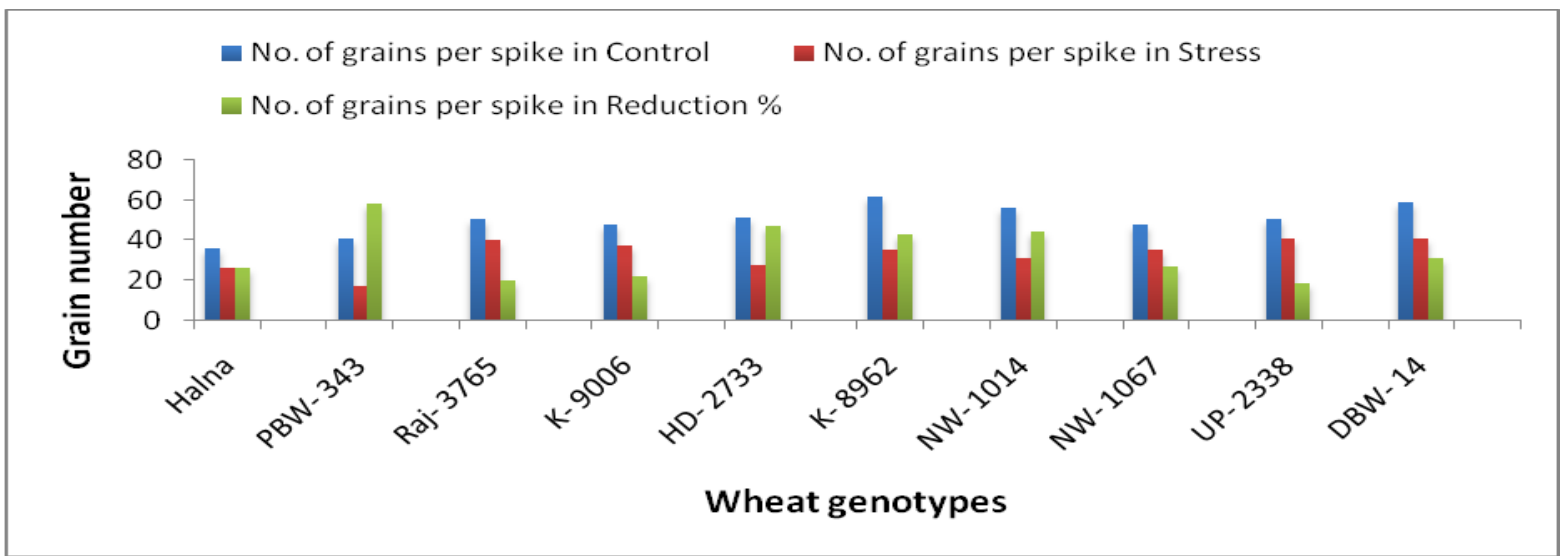

Fig.8 Yield per plant (g) and its percent reduction of wheat genotypes over control under heat stress condition

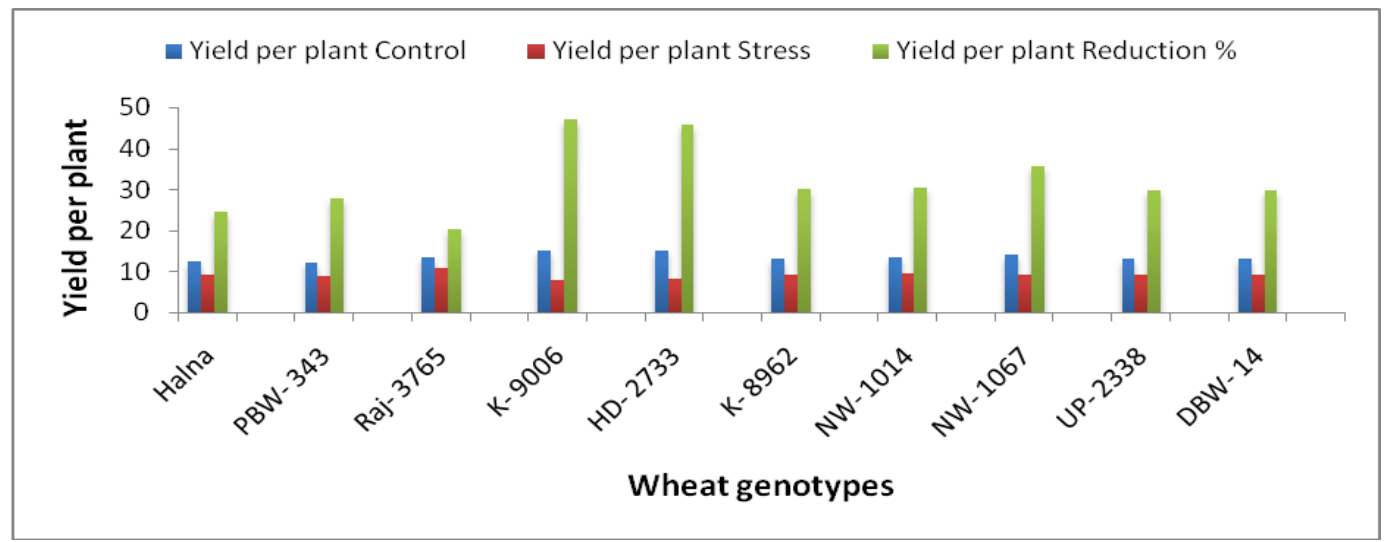


Fig.9 Test weight (g) and its percent reduction of wheat genotypes over control under heat stress condition

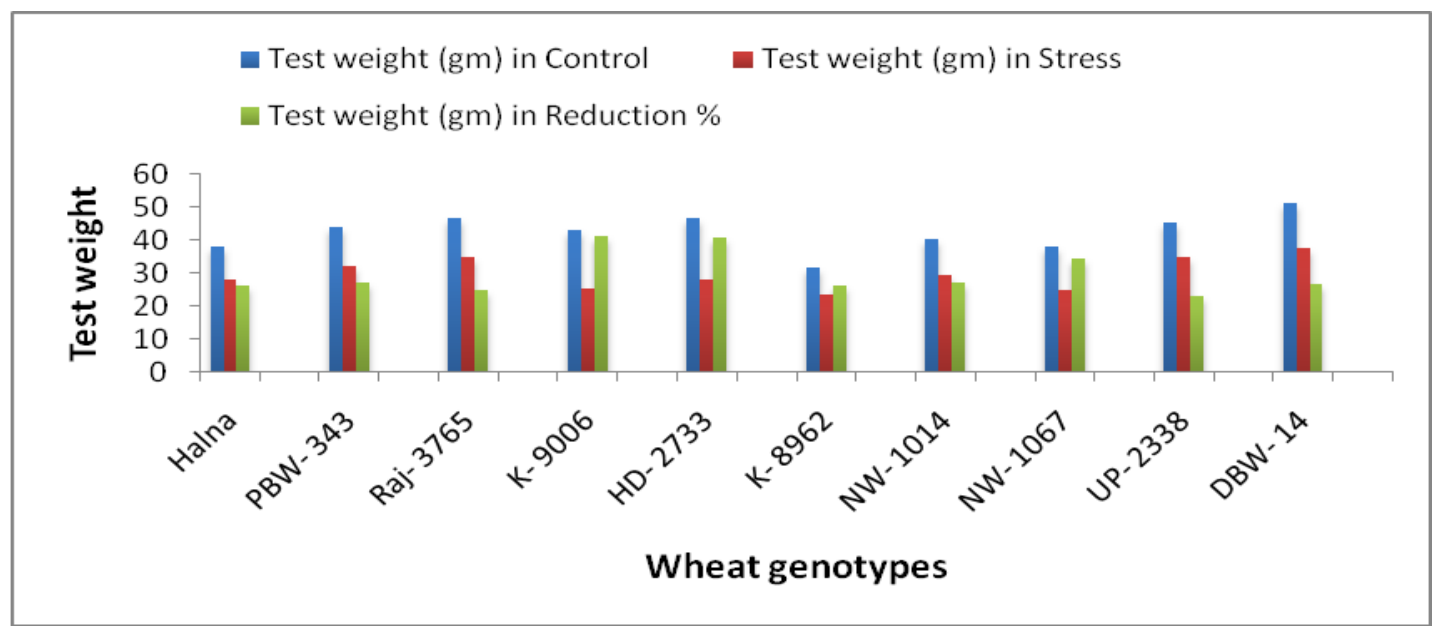

In conclusion, the heat tolerant wheat genotypes showed high MSI, CSI, stay green condition and CTD and less reduction in yield and yield component under heat stress condition. In the present investigation it may be concluded that Halna is tolerant wheat genotype followed by K-8962 and Raj-3765, DBW-14, NW-1014 under moderate to high heat stress condition. Although, variety like HD-2733, K-9006 and NW-1067 gave high yield under controlled condition but it also showed high susceptibility to heat stress in all respect.

\section{Acknowledgement}

Authors are very thankful to Department of Plant Molecular Biology and Genetic Engineering for providing facility during research work.

\section{References}

Ali, N., Dayal, A., Lal, G. M., Thomas, N. and Singh, T., (2018). Effect of Early and Mid Sowing on Growth and Yield of Wheat (Triticum aestivum L.) Varieties. Int. J. Pure Appl. Biosci., 6(3): 403-409.

Balota, M., Payne, W. A., Evett, S. R., Lazar,
M. D. (2007). Canopy temperature depression sampling to assess grain yield and genotypic differentiation in winter wheat. Crop Sci., 47: 15181529 .

Chauhan, H., Khurana, N., Tyagi, A. K., Khurana, J. P., Khurana, P. (2010). Identification and characterization of high temperature stress responsive genes in bread wheat (Triticum aestivum L.) and their regulation at various stages of development. $\mathrm{Pl}$. Mole. Biol., 8: 1-17.

Cossani, C. M., Reynolds, M. P. (2012) Physiological traits for improving heat tolerance in wheat. Pl. Physiol., 160: 1710-1718.

Dwivedi, R., Prasad, S., Jaiswal, B., Kumar, A., Tiwari, A., Patel, S., Pandey, S. and Pandey, G. (2017). Evaluation of Wheat Genotypes (Triticum aestivum L.) at Grain Filling Stage for Heat Tolerance. Int. J. Pure App. Biosci., 5(2): 971-975.

Dhopte, A. M. and Livera, M. M. (1989). Useful Techniques for Plant Scientists, Forum for Plant Physiologists, Murly Printers, Shivnagar, Akola.

Fukuoka, M. (2005). Improvement of a Method for Measuring Canopy 
Temperature in Field Crops Using an Infrared Thermograph. Hokkaido University, Sapporo, Japan, 1-45.

Hansen, J., Sato, M. and Ruedy, R. (2012).

Perception of climate change. Proc. of the Nati. Aca. of Sci., 109(37): 24152423.

Kumar, M., Singh, A. K., Raina, S. K., Govindasamy, V., Choudhary, R. L., Rane, J. and Minhas, P. S. (2015). Thermal imaging to assess genetic variation in drought adaptation of soybean cultivars. $3 r d$ Int. Pl. Physiol. Confe., p. 120.

Larkindale, J., Knight, M. R. (2002). Protection against heat stress-induced oxidative damage in Arabidopsis involves calcium, abscisic acid, ethylene, and salicylic acid. $P l$. Physiol., 128: 682-695.

Limbalkar, O. M., Meena, V. K., Singh, M and Sunilkumar, V. P. (2018). Genetic Improvement of Wheat for Biotic and Abiotic Stress Tolerance. Int. J. Curr. Microbiol. Appl. Sci., 7(12): 19621971.

Moriondo, M., Giannakopoulos, C. and Bindi, M. (2011). Climate change impact assessment: the role of climate extremes in crop yield simulation.
Climatic change, 104(3-4): 679-701.

Ramadas, S., Kumar, T. M. K. and Singh, G. P. (2019). Wheat Production in India: Trends and Prospects. Intechopen., 8634.

Sairam, R. K. (1994). Effect of moisture stress on physiological activities of two contrasting wheat genotypes. Ind. J. Exp. Biol., 32: 594-597.

Sharma, S., Sahu, V.S. and Dhindsa, G.S. (2001). Genetic variation for foliar traits in wheat varieties exposed to different thermal regimes. In Kharwal, N.C. and Mehra, R.B. (Eds.) Hundred years of Post-Mendelian genetics and Plant Breeding Retrospect and Prospects. Sym. Proc., p. 165, New Delhi.

Wardlaw, I., Dawson, I., Munibi, P. and Fewster, R. (1989). The tolerance of wheat to high temperatures during reproductive growth. I. Survey procedures and general response patterns. Aust. J. of Agri. Res., 40(1): 1.

Wang, F., Wang, G., Li, X., Huang, J., Zheng, J. (2008). Heredity, physiology and mapping of a chlorophyll content gene of rice (Oryza sativa L.). J. Pl. Physiol., 165(3): 324-30.

\section{How to cite this article:}

Prabhat Kumar Singh, Shambhoo Prasad, Abhishek Kumar Verma, Babu Lal, Reesu Singh, Sumant Pratap Singh and Dwivedi, D. K. 2020. Screening for Heat Tolerant Traits in Wheat (Triticum aestivum L.) Genotypes by Physio-biochemical Markers. Int.J.Curr.Microbiol.App.Sci. 9(02): 2335-2343. doi: https://doi.org/10.20546/ijcmas.2020.902.265 